\title{
Bronchial inflammation and bacterial load in stable COPD is associated with TLR4 overexpression
}

\author{
Antonino Di Stefano (10) ${ }^{1}$, Fabio L.M. Ricciardolo², Gaetano Caramori (1) ${ }^{3}$, \\ Ian M. Adcock ${ }^{4}$, Kian Fan Chung ${ }^{4}$, Peter J. Barnes ${ }^{4}$, Paola Brun ${ }^{5}$, \\ Andrea Leonardi ${ }^{6}$, Filippo Andò (107, Davide Vallese ${ }^{1}$, Isabella Gnemmi ${ }^{1}$, \\ Luisella Righi $^{8}$, Francesco Cappello 9,10 and Bruno Balbi ${ }^{1}$
}

\begin{abstract}
Affiliations: 'Divisione di Pneumologia e Laboratorio di Citoimmunopatologia dell'Apparato Cardio Respiratorio, Istituti Clinici Scientifici Maugeri SpA, Società Benefit, Veruno, Italy. ${ }^{2}$ Dipartimento di Scienze Cliniche e Biologiche, AOU, San Luigi, Orbassano, Università di Torino, Turin, Italy. ${ }^{3}$ Centro Interdipartimentale per lo Studio delle Malattie Infiammatorie delle Vie Aeree e Patologie Fumo-correlate (CEMICEF), Sezione di Medicina Interna e Cardiorespiratoria, Università di Ferrara, Ferrara, Italy. ${ }^{4}$ Airways Disease Section, National Heart and Lung Institute, Imperial College London, London, UK. ${ }^{5}$ Dipartimento di Medicina Molecolare, Università di Padova, Padua, Italy. ${ }^{6}$ Dept of Neuroscience, Ophthalmology Unit, University of Padua, Padua, Italy. ${ }^{7} \mathrm{UOC}$ di Malattie Respiratorie, Dipartimento di Scienze Biomediche, Odontoiatriche e delle Immagini Morfologiche e Funzionali, Università di Messina, Messina, Italy. ${ }^{8}$ Dipartimento di Oncologia, SCDU, Anatomia Patologica, AOU, San Luigi, Orbassano, Università di Torino, Turin, Italy. ${ }^{9}$ Dipartimento di Biomedicina Sperimentale e Neuroscienze Cliniche, Sezione di Anatomia Umana, Università di Palermo, Palermo, Italy. ${ }^{10}$ Euro-Mediterranean Institute of Science and Technology (IEMEST), Palermo, Italy.
\end{abstract}

Correspondence: Antonino Di Stefano, Istituti Clinici Scientifici Maugeri, IRCCS, Divisione di Pneumologia e Laboratorio di Citoimmunopatologia dell'Apparato Cardio Respiratorio, Via per Revislate 13, 28010 Veruno, Italy. E-mail: antonino.distefanodicsmaugeri.it

@ERSpublications

Inflammation, bacterial load and active antibacterial immune response involving TLR4 and NOD1 in stable COPD http://ow.ly/S1fp308qcwp

Cite this article as: Di Stefano A, Ricciardolo FLM, Caramori G, et al. Bronchial inflammation and bacterial load in stable COPD is associated with TLR4 overexpression. Eur Respir J 2017; 49: 1602006 [https://doi.org/10.1183/13993003.02006-2016].

ABSTRACT Toll-like receptors (TLRs) and nucleotide-binding oligomerisation domain (NOD)-like receptors (NLRs) are two major forms of innate immune sensors but their role in the immunopathology of stable chronic obstructive pulmonary disease (COPD) is incompletely studied. Our objective here was to investigate TLR and NLR signalling pathways in the bronchial mucosa in stable COPD.

Using immunohistochemistry, the expression levels of TLR2, TLR4, TLR9, NOD1, NOD2, CD14, myeloid differentiation primary response gene 88 (MyD88), Toll-interleukin-1 receptor domain-containing adaptor protein (TIRAP), and the interleukin-1 receptor-associated kinases phospho-IRAK1 and IRAK4 were measured in the bronchial mucosa of subjects with stable COPD of different severity $(\mathrm{n}=34)$, control smokers $(\mathrm{n}=12)$ and nonsmokers $(\mathrm{n}=12)$. The bronchial bacterial load of Pseudomonas aeruginosa, Haemophilus influenzae, Moraxella catarrhalis and Streptococcus pneumoniae was measured by quantitative real-time PCR.

TLR4 and NOD1 expression was increased in the bronchial mucosa of patients with severe/very severe stable COPD compared with control subjects. TLR4 bronchial epithelial expression correlated positively with $\mathrm{CD}^{+}$and $\mathrm{CD}^{+}$cells and airflow obstruction. NOD1 expression correlated with $\mathrm{CD}^{+}$cells. The bronchial load of $P$. aeruginosa was directly correlated, but $H$. influenzae inversely correlated, with the degree of airflow obstruction. Bacterial load did not correlate with inflammatory cells.

Bronchial epithelial overexpression of TLR4 and NOD1 in severe/very severe stable COPD, associated with increased bronchial inflammation and $P$. aeruginosa bacterial load, may play a role in the pathogenesis of COPD. 


\section{Introduction}

Inflammation plays a key role in the pathogenesis of chronic obstructive pulmonary disease (COPD) [1]. A symbiotic relationship between the microbiota and the innate and adaptive immune host response has been postulated $[2,3]$. Immune host responses to microbiota challenges are balanced in such a way as to maintain the microbiota diversity required for induction of protective responses to pathogens $[2,3]$. The innate immune system recognises microbial pathogens through pattern recognition receptors (PRRs), which detect the pathogen-associated molecular patterns (PAMPs) and induce inflammatory host responses and activation of the adaptive immune responses $[2,3]$.

Toll-like receptors (TLRs) and nucleotide-binding oligomerisation domain (NOD)-like receptors (NLRs) are two major PRRs, which provide responses against pathogenic invasion or tissue injury [4]. TLR2 recognises lipoteichoic acid (LTA) from Gram-positive bacteria and some nontypical lipopolysaccharides (LPSs) of Gram-negative bacteria [5]; TLR4 recognises LPS and some endogenous ligands [5], and TLR9 is involved in viral A/D- and bacterial B/K-type CpG DNA recognition [6]. CD14 acts as a coreceptor (along with TLR4) for the detection of LPS but can bind LPS only in the presence of LPS-binding protein. Although LPS is considered its main ligand, CD14 also recognises other PAMPs such as LTA [7].

NOD1 and NOD2 recognise intracellular bacteria through identification of peptidoglycan components, such as a muramyl dipeptide found in almost all bacteria, or via $\gamma$-D-glutamyl-meso-diaminopimelic acid found in Gram-negative bacteria [8]. Both myeloid differentiation primary response gene 88 (MyD88)-dependent and -independent (involving the CD14) signalling pathways are activated downstream of TLR activation [9, 10]. Upon receptor stimulation, MyD88 recruits interleukin-1 receptor-associated kinase (IRAK) family member IRAK4 to TLRs and induces IRAK1 phosphorylation, followed, in turn, by activator protein AP-1 activation and nuclear translocation and/or I $\mathrm{B}$ degradation and NF- $\kappa \mathrm{B}$ nuclear activation [11-14]. Toll-interleukin-1 receptor domain-containing adaptor protein (TIRAP) is essential for the MyD88-dependent signalling pathway through TLR2 and TLR4 activation [15].

Abnormalities in any of these innate sensor-mediated processes may result in excessive inflammation due to either hyperactive innate immune signalling or sustained compensatory adaptive immune activation $[4,5]$. These characteristics have been observed in the lower airways of patients with stable COPD [1]. We hypothesise the detection of bacterial proteins occurs to a greater extent in more severe COPD. The aim of this study was to investigate TLR and NLR signalling pathways in the bronchial mucosa in relation to the bronchial bacterial load of patients with stable COPD of differing severity and control subjects.

\section{Methods}

\section{Subjects}

All COPD patients and control subjects who underwent bronchoscopy and bronchial biopsies were recruited from the Respiratory Medicine Unit of the Fondazione Salvatore Maugeri, Institute of Veruno (Veruno, Italy). In COPD patients, the severity of airflow obstruction was graded using current Global Initiative for Chronic Obstructive Lung Disease (GOLD) criteria (http://goldcopd.org). All former smokers had stopped smoking for at least 1 year. COPD and chronic bronchitis were defined according to international guidelines (http://goldcopd.org). All COPD patients were stable with no exacerbation in the 6 months prior to bronchoscopy. None of the subjects was treated with theophylline, antibiotics, antioxidants, mucolytics and/or glucocorticoids in the month prior to bronchoscopy. The study conformed to the Declaration of Helsinki, and was approved by the ethics committees of the Fondazione Salvatore Maugeri (Veruno, Italy) and the University Hospital of Ferrara (Ferrara, Italy). Written informed consent was obtained from each subject and bronchial biopsies were performed according to the local ethics committee guidelines.

A detailed description of subjects, lung function tests, fibreoptic bronchoscopy and processing of bronchial biopsies, immunohistochemistry, scoring system for immunohistochemistry, double staining, quantification of bacterial load, in vitro experiments performed on normal human bronchial epithelial cells, and details of statistical analysis are provided in the supplementary material.

This article has supplementary material available from erj.ersjournals.com

Received: Oct 122016 | Accepted after revision: Jan 202017

Support statement: This work was supported by Istituti Clinici Scientifici Maugeri, SpA Società Benefit, Ricerca Corrente. I.M. Adcock and P.J. Barnes are supported by Wellcome Trust grant 093080/Z/10/Z. I.M. Adcock, K.F. Chung and P.J. Barnes are supported by the National Institute for Health Research (NIHR) Respiratory Disease Biomedical Research Unit at the Royal Brompton and Harefield NHS Foundation Trust and Imperial College London. Funding information for this article has been deposited with the Open Funder Registry. The views expressed in this publication are those of the authors and not necessarily those of the NHS, the NIHR or the Dept of Health.

Conflict of interest: Disclosures can be found alongside this article at erj.ersjournals.com 


\section{Statistical analysis}

The numbers of patients used in each group was based on previous studies which examined differences in inflammatory cell numbers in bronchial biopsies [16]. Differences between groups were analysed using ANOVA for functional data. The ANOVA test was followed by the unpaired t-test for comparison between groups. The Kruskal-Wallis test applied for morphological data was followed by the Mann-Whitney U-test for comparison between groups. Correlation coefficients were calculated using the Spearman rank method. Probability values of $\mathrm{p}<0.05$ were considered significant.

\section{Results}

\section{Clinical characteristics of the subjects}

We obtained and studied bronchial biopsies from 58 subjects: 34 with stable COPD, 12 control smokers with normal lung function and 12 nonsmokers with normal lung function (table 1). COPD patients were divided into two groups: mild/moderate (GOLD stage I-II, $n=16$ ) and severe/very severe (GOLD stage IIIIV, $\mathrm{n}=18$ ). There was no difference in age between the subjects in the four groups. The smoking history was similar in the three smoking groups. Values of forced expiratory volume in $1 \mathrm{~s}$ (FEV1) \% pred and FEV 1 /forced vital capacity (FVC) \% differed significantly between total COPD patients (mild/moderate and severe/very severe) and both control groups (healthy smokers and healthy nonsmokers). Lung function in severe/very severe COPD patients also differed significantly from mild/moderate COPD patients (ANOVA: $\mathrm{p}<0.0001$ for FEV1 \% pred and FEV1/FVC \% values). 35\% $(\mathrm{n}=12)$ of the total COPD patients and $25 \%(n=3)$ of healthy smokers with normal lung function also had symptoms of chronic bronchitis but this was not significant.

\section{Inflammatory cells in the bronchial biopsies}

The results of the immunohistochemical analysis are summarised in table 2. These data, obtained from stable COPD patients, confirm previously reported results showing higher numbers of neutrophils in severe/very severe COPD (table 2) [16]. There was also a trend towards increased $\mathrm{CD}^{+}$cell numbers in severe and very severe patients but this did not reach significance according to the Kruskal-Wallis test. COPD patients with chronic bronchitis had a similar number of neutrophils when compared with COPD patients without chronic bronchitis $[16,17]$.

\section{Immunohistochemistry}

The results of the immunohistochemical study for the TLR and NLR signalling pathways are summarised in table 2 .

\section{Immunohistochemistry in the bronchial epithelium}

The expression of TLR4 in the bronchial epithelium was increased in severe/very severe stable COPD compared with nonsmoking control subjects ( $\mathrm{p}=0.0027)$ (table 2 and supplementary figure E1). There was a trend towards significance between these COPD patients and control smokers with normal lung function $(p=0.054)$. The expression of TLR4 in the bronchial epithelium was also increased in mild/moderate stable COPD patients compared with nonsmoking control subjects $(\mathrm{p}=0.024)$. Similarly, the expression of NOD1 in the bronchial epithelium was increased in severe/very severe stable COPD compared with mild/moderate stable COPD patients $(\mathrm{p}=0.036)$ and nonsmoking control subjects $(\mathrm{p}=0.006)$ (table 2 and supplementary

\begin{tabular}{|c|c|c|c|c|c|c|c|c|}
\hline Groups & Subjects $\mathrm{n}$ & Age years & $M / F$ & Pack-years & $\begin{array}{c}\text { Ex-/current } \\
\text { smoker }\end{array}$ & $\begin{array}{l}\text { FEV } 1 \% \text { pred } \\
\text { pre-BD }\end{array}$ & $\begin{array}{l}\text { FEV } 1 \% \text { pred } \\
\text { post-BD }\end{array}$ & $\mathrm{FEV}_{1} / \mathrm{FVC} \%$ \\
\hline Control nonsmokers & 12 & $63 \pm 13$ & $10 / 2$ & 0 & 0 & $117 \pm 18$ & ND & $86 \pm 10$ \\
\hline $\begin{array}{l}\text { Control smokers with } \\
\text { normal lung function }\end{array}$ & 12 & $61 \pm 7$ & $9 / 3$ & $43 \pm 26$ & $2 / 10$ & $104 \pm 13$ & ND & $81 \pm 6$ \\
\hline COPD stages III and IV & 18 & $66 \pm 9$ & $11 / 7$ & $54 \pm 36$ & $13 / 5$ & $35 \pm 8^{\#, 9}$ & $38 \pm 9$ & $44 \pm 10^{\#, 9}$ \\
\hline
\end{tabular}

Data are presented as mean \pm SD, unless otherwise stated. M: male; F: female; FEV1: forced expiratory volume in 1 s; BD: bronchodilator; FVC: forced vital capacity; ND: not determined. Patients were classified according to Global Initiative for Chronic Obstructive Lung Disease (http://goldcopd.org) levels of severity for COPD: mild (stage I), moderate (stage II), severe (stage III) and very severe (stage IV). For COPD patients FEV1/FVC \% are post-bronchodilator values. ${ }^{\#}$ : $p<0.0001$, significantly different from control smokers with normal lung function and control never-smokers (ANOVA); ๆ: p<0.0001, significantly different from mild/moderate COPD (ANOVA). 
figure E2). NOD1 expression also trended towards significance between severe/very severe stable COPD patients and control smokers with normal lung function $(\mathrm{p}=0.054)$.

The bronchial epithelial expression of both MyD88 (Kruskal-Wallis: $\mathrm{p}=0.059$; Mann-Whitney: $\mathrm{p}=0.012$ and $\mathrm{p}=0.038$, respectively) and TIRAP (Kruskal-Wallis: $\mathrm{p}=0.082$; Mann-Whitney: $\mathrm{p}=0.035$ and $\mathrm{p}=0.047$, respectively) also tended to be increased in severe/very severe stable COPD patients compared with mild/ moderate COPD and control smokers with normal lung function (table 2). No significant differences were observed for the other molecules studied (table 2). These data are also summarised in figure 1a.

\section{Immunohistochemistry in bronchial lamina propria}

TLR4 was increased in severe/very severe COPD $(\mathrm{p}=0.027)$ and mild/moderate COPD $(\mathrm{p}=0.015)$ compared with control smokers (table 2 and supplementary figure E1). NOD1 was increased in severe/ very severe COPD compared with control smokers $(\mathrm{p}=0.022)$ and control nonsmokers $(\mathrm{p}=0.002)$. It was also increased in mild/moderate $\operatorname{COPD}(\mathrm{p}=0.023)$ compared with control nonsmokers (table 2 and supplementary figure E2). IRAK4 tended to be increased in mild/moderate COPD (Kruskal-Wallis: $\mathrm{p}=0.071$; Mann-Whitney: $\mathrm{p}=0.017$ ) compared with control smokers (table 2). No statistical differences were observed for the other molecules studied (table 2). These data are summarised in figure 1b. Double staining for identification of $\mathrm{CD}^{+}$(T-cells), $\mathrm{CD}^{+} 8^{+}$(macrophages) and $\mathrm{CD} 31^{+}$(endothelial cells) cells co-expressing TLR4 and NOD1 was performed in three representative COPD patients. The mean \pm SE percentages of $\mathrm{CD}^{+}{ }^{\mathrm{TLR}^{+}}{ }^{+}, \mathrm{CD} 68^{+} \mathrm{TLR}^{+}{ }^{+}$and $\mathrm{CD} 31^{+} \mathrm{TLR}^{+}$double-stained cells were $51 \pm 11 \%, 54 \pm 12 \%$ and $61 \pm 5 \%$, respectively; the mean \pm SE percentages of $\mathrm{CD}^{+} \mathrm{NOD}^{+}, \mathrm{CD} 68^{+} \mathrm{NOD}^{+}$and $\mathrm{CD} 31^{+} \mathrm{NOD}^{+}$ double-stained cells were $31 \pm 10 \%, 30 \pm 5 \%$ and $43 \pm 5 \%$, respectively (supplementary figure E3).

TABLE 2 Immunohistochemical quantification of innate immune molecules and cytokines related to bacterial response in bronchial biopsies

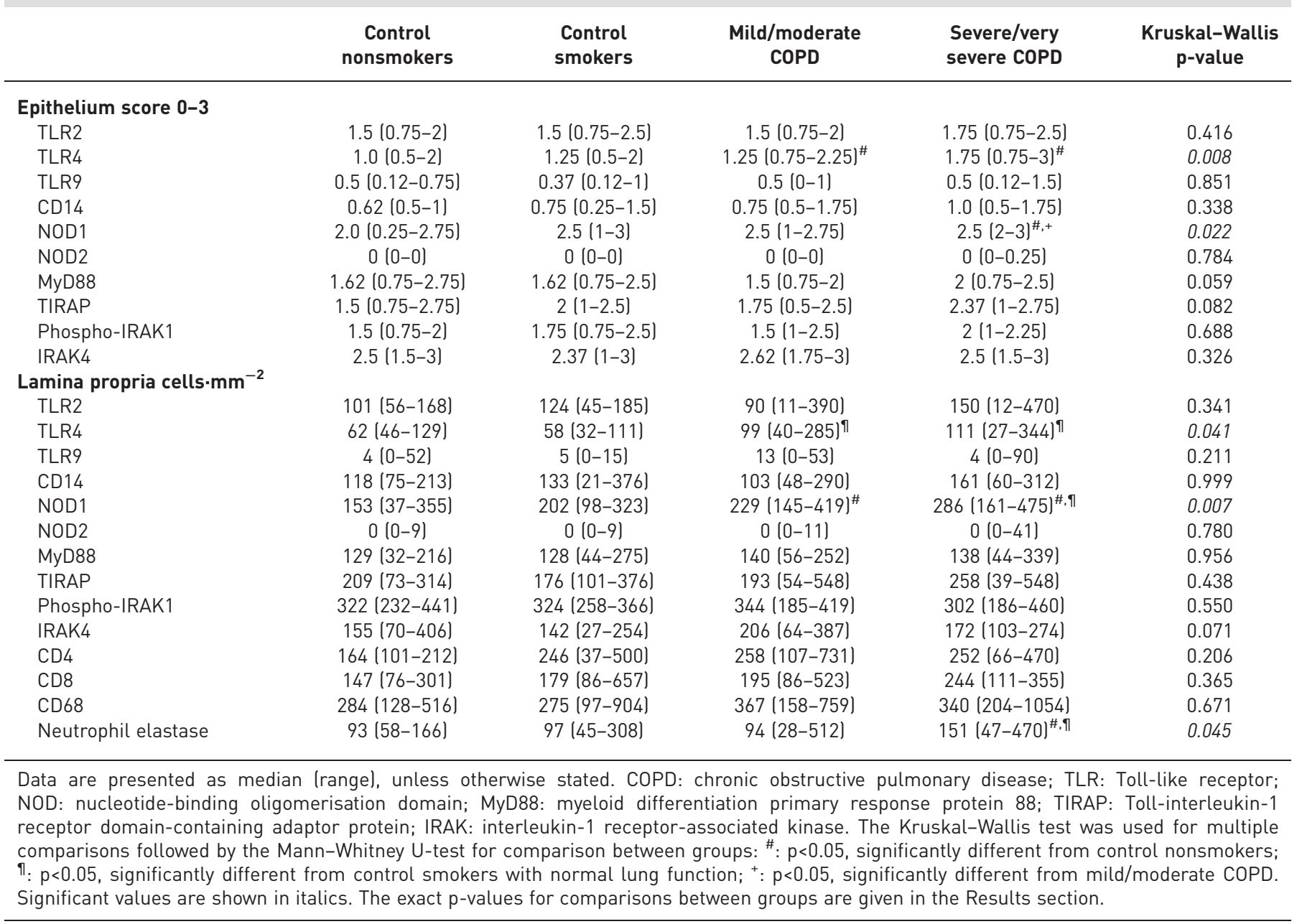


Quantification of bacterial load in the bronchial biopsies

The results of the quantification of the bacterial load in the bronchial biopsies are summarised in table 3 and figure $1 c$. When data were expressed as absolute numbers, $H$. influenzae was decreased in severe/very severe COPD compared with mild/moderate COPD $(\mathrm{p}=0.011)$ and control smokers $(\mathrm{p}=0.0013)$. No significant differences were observed for P. aeruginosa, M. catarrhalis and S. pneumoniae (table 3). To evaluate changes in the relative proportions of each bacterium studied, we expressed these data as percentage of the total load value constituted by the sum of the four bacteria studied. The percentage of $P$. aeruginosa tended to be increased in severe/very severe stable COPD compared with control smokers with normal lung function (Kruskal-Wallis: $p=0.050$; Mann-Whitney: $p=0.012$ ); the percentage of $H$. influenzae was significantly decreased in severe/very severe COPD compared with mild/moderate COPD $(\mathrm{p}=0.029)$ and control smokers $(\mathrm{p}=0.010)$ (table 3 and figure $1 \mathrm{c})$.

Quantification of TLR4 MRNA in in vitro $\mathrm{H}_{2} \mathrm{O}_{2}$-treated bronchial epithelial cells

Bronchial epithelial $(16 \mathrm{HBE})$ cells treated with $\mathrm{H}_{2} \mathrm{O}_{2}(100 \mu \mathrm{M})$ showed significantly increased TLR4 mRNA levels after $2 \mathrm{~h}$ (figure $1 \mathrm{~d}$ ).
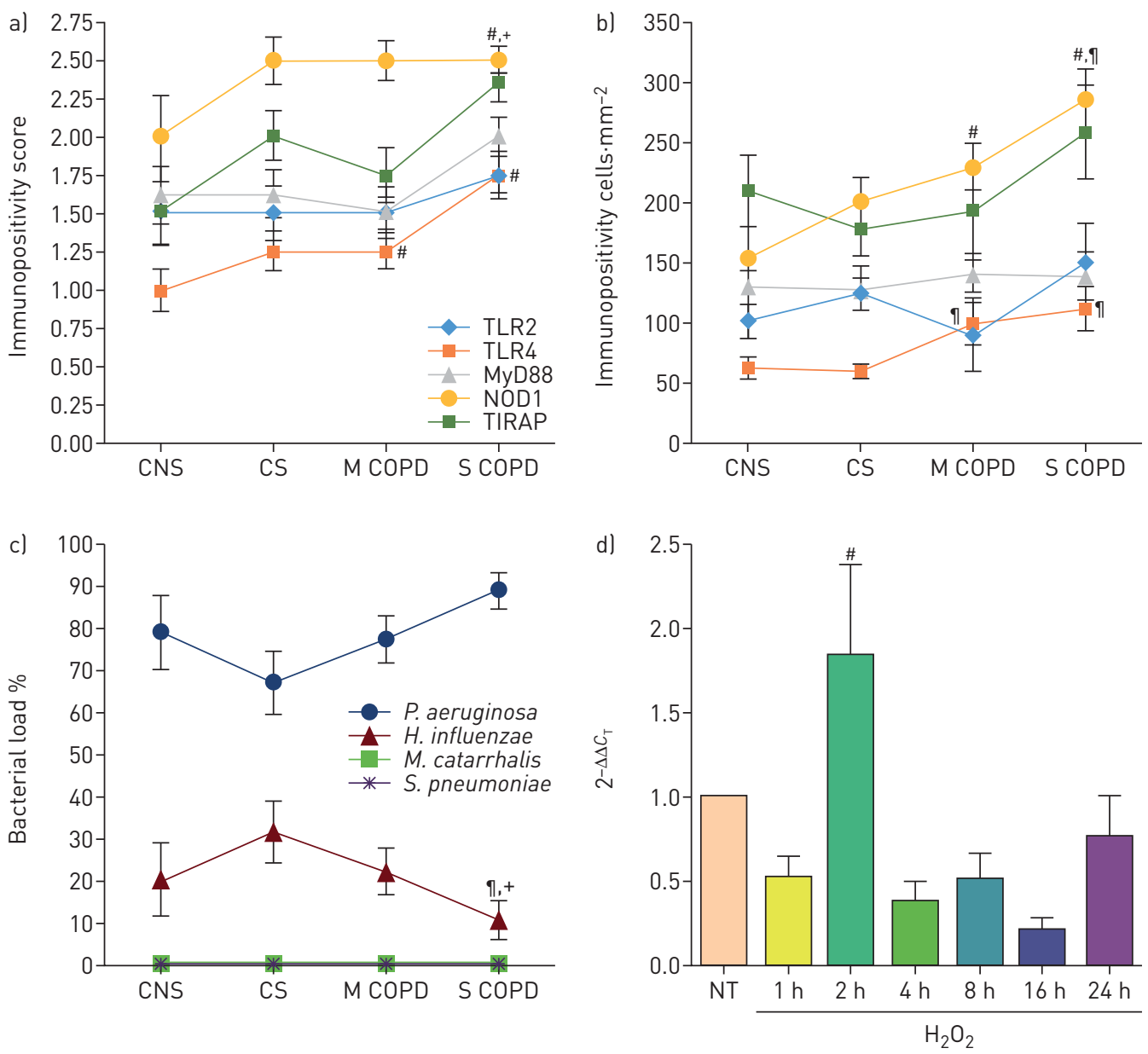

FIGURE $1 \mathrm{a}, \mathrm{b}$ ) Schematic representation of the molecular variations related to bacterial-related molecules in the a) bronchial epithelium and b) bronchial lamina propria of control nonsmokers (CNS), control smokers (CS), mild/moderate stable chronic obstructive pulmonary disease (M COPD) and severe/very severe stable COPD (S COPD) patients. TLR: Toll-like receptor; MyD88: myeloid differentiation primary response gene 88; NOD: nucleotide-binding oligomerisation domain; TIRAP: Toll-interleukin-1 receptor domain-containing adaptor protein. With worsening of the disease, levels of TLR4 and NOD1 increase in the bronchial epithelium and bronchial lamina propria. c) Pseudomonas aeruginosa and Haemophilus influenzae variations in control subjects and in COPD patients of increasing severity. M. catarrhalis: Moraxella catarrhalis; S. pneumoniae: Streptococcus pneumoniae. With worsening of the disease, levels of $P$. aeruginosa increase, while levels of $H$. influenzae decrease in bronchial biopsies. d) TLR4 mRNA significant increase induced by $\mathrm{H}_{2} \mathrm{O}_{2}$ stimulation of bronchial epithelial cells (16HBE) at $2 \mathrm{~h}$ after oxidative stimulus. NT: not treated. See the supplementary material for further details about the immunohistochemistry, quantification of bacterial load and in vitro experiments. Data are presented as median \pm SE. " : significantly different from CNS; ": significantly different from $\mathrm{CS}^{+}{ }^{+}$: significantly different from M COPD. 
TABLE 3 Bacterial load in bronchial biopsies of chronic obstructive pulmonary disease (COPD) patients and control subjects

\begin{tabular}{|c|c|c|c|c|c|}
\hline & $\begin{array}{c}\text { Control } \\
\text { nonsmokers }\end{array}$ & $\begin{array}{l}\text { Control } \\
\text { smokers }\end{array}$ & $\begin{array}{c}\text { Mild/moderate } \\
\text { COPD }\end{array}$ & $\begin{array}{l}\text { Severe/very } \\
\text { severe COPD }\end{array}$ & $\begin{array}{c}\text { Kruskal-Wallis } \\
\text { p-value }\end{array}$ \\
\hline Subjects & 5 & 9 & 13 & 15 & \\
\hline \multirow[t]{2}{*}{ Pseudomonas aeruginosa } & $167 \pm 157$ & $117 \pm 122$ & $143 \pm 149$ & $61 \pm 62$ & 0.451 \\
\hline & (78.8 \pm 23.3$)$ & $(67.2 \pm 22.6)$ & $(77.2 \pm 23.9)$ & $(88.8 \pm 20.2)$ & $(0.050)$ \\
\hline Haemophilus influenzae & $42 \pm 59$ & $51 \pm 74$ & $28 \pm 38$ & $5 \pm 8^{\text {ๆl, }}+$ & 0.007 \\
\hline Moraxella catarrhalis & $(0.6 \pm 1.3)$ & $(0.7 \pm 1.9)$ & $(0.07 \pm 0.26)$ & $(0.47 \pm 1.25)$ & (0.924) \\
\hline \multirow[t]{2}{*}{ Streptococcus pneumoniae } & $0.06 \pm 0.13$ & $0.0 \pm 0.0$ & $0.11 \pm 0.34$ & $0.0 \pm 0.0$ & 0.710 \\
\hline & $(0.0 \pm 0.0)$ & $(0.0 \pm 0.0)$ & $(0.07 \pm 0.26)$ & $(0.0 \pm 0.0)$ & $(0.986)$ \\
\hline \multicolumn{6}{|c|}{$\begin{array}{l}\text { Data expressed as } \mathrm{n} \text { or mean } \pm \mathrm{SE} \text {, unless otherwise stated. The bacterial load (copies. } \mathrm{mL}^{-1} \text { ) is normalised for the bronchial biopsy superficial } \\
\text { layer }\left(\mathrm{mm}^{2} \text { ). The percentage of each bacterial species studied over the total load value (i.e. P. aeruginosa plus } H \text {. influenzae plus } M \text {. catarrhalis }\right. \\
\text { plus S. pneumoniae) is shown in parentheses. The Kruskal-Wallis test was used for multiple comparisons followed by the Mann-Whitney U-test } \\
\text { for comparison between groups: ?: } \mathrm{p}<0.05 \text {, significantly different from control smokers with normal lung function; }{ }^{+} \text {: } p<0.05, \text { significantly } \\
\text { different from mild/moderate COPD. The exact } p \text {-values for comparison between groups are given in the Results section. }\end{array}$} \\
\hline
\end{tabular}

Correlations between clinical parameters, number of inflammatory cells, TLR and NLR signalling pathway expression, and bacterial load in the bronchial biopsies

In all smokers, the degree of TLR4 immunostaining in the bronchial epithelium was positively correlated with the numbers of $\mathrm{CD}^{+}$cells $(\mathrm{r}=0.630 ; \mathrm{p}=0.018)$ and $\mathrm{CD} 4^{+}$cells $(\mathrm{r}=0.580 ; \mathrm{p}=0.029)$ in the bronchial lamina propria. In addition, in all smokers, the degree of TLR4 immunostaining in the bronchial epithelium was inversely correlated with FEV1 \% pred $(\mathrm{r}=-0.36 ; \mathrm{p}=0.019)$ and FEV1/FVC \% $(\mathrm{r}=-0.39$; $\mathrm{p}=0.009)$. When the analysis was restricted to patients with stable COPD alone, the correlations between the degree of TLR4 immunostaining in the bronchial epithelium with $\mathrm{FEV}_{1} \%$ pred $(\mathrm{r}=-0.37 ; \mathrm{p}=0.037)$ and $\mathrm{FEV} 1 / \mathrm{FVC} \%(\mathrm{r}=-0.50 ; \mathrm{p}=0.005)$ were maintained (figure 2$)$. In all smokers, NOD1 immunostaining
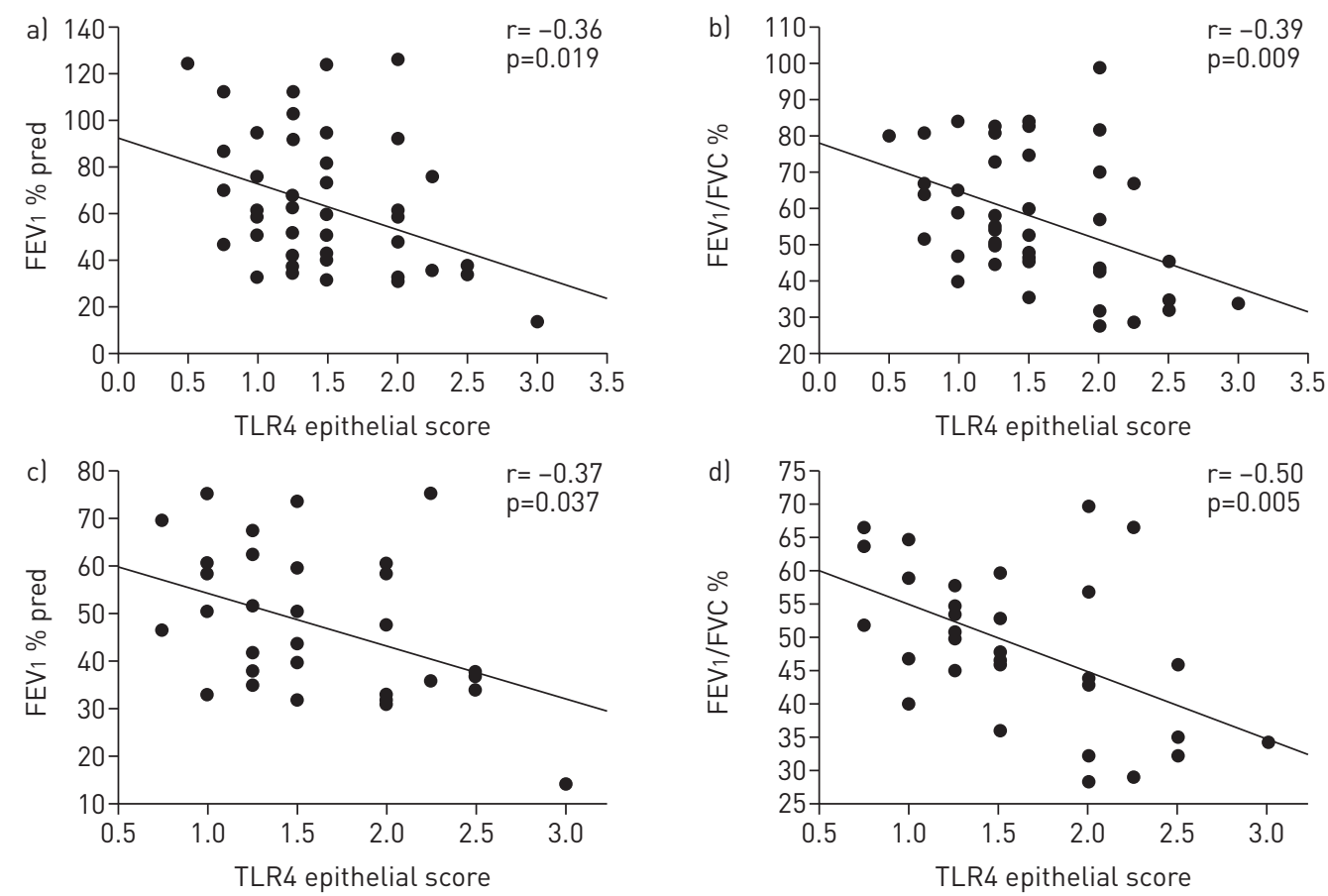

FIGURE 2 Regression analysis performed in a, b) all smokers and c, d) patients with chronic obstructive pulmonary disease (COPD) alone showing correlations between Toll-like receptor 4 (TLR4) scored epithelial values and $a, c)$ forced expiratory volume in $1 \mathrm{~s}\left(\mathrm{FEV}_{1}\right) \%$ pred and $\left.b, d\right) \mathrm{FEV}_{1} /$ forced vital capacity (FVC) \%. The lung functional indices of bronchial obstruction were significantly and inversely correlated with the immune expression of TLR4 in the bronchial epithelium of all smokers and of patients with COPD alone. Correlation coefficients were calculated using the Spearman rank method. 

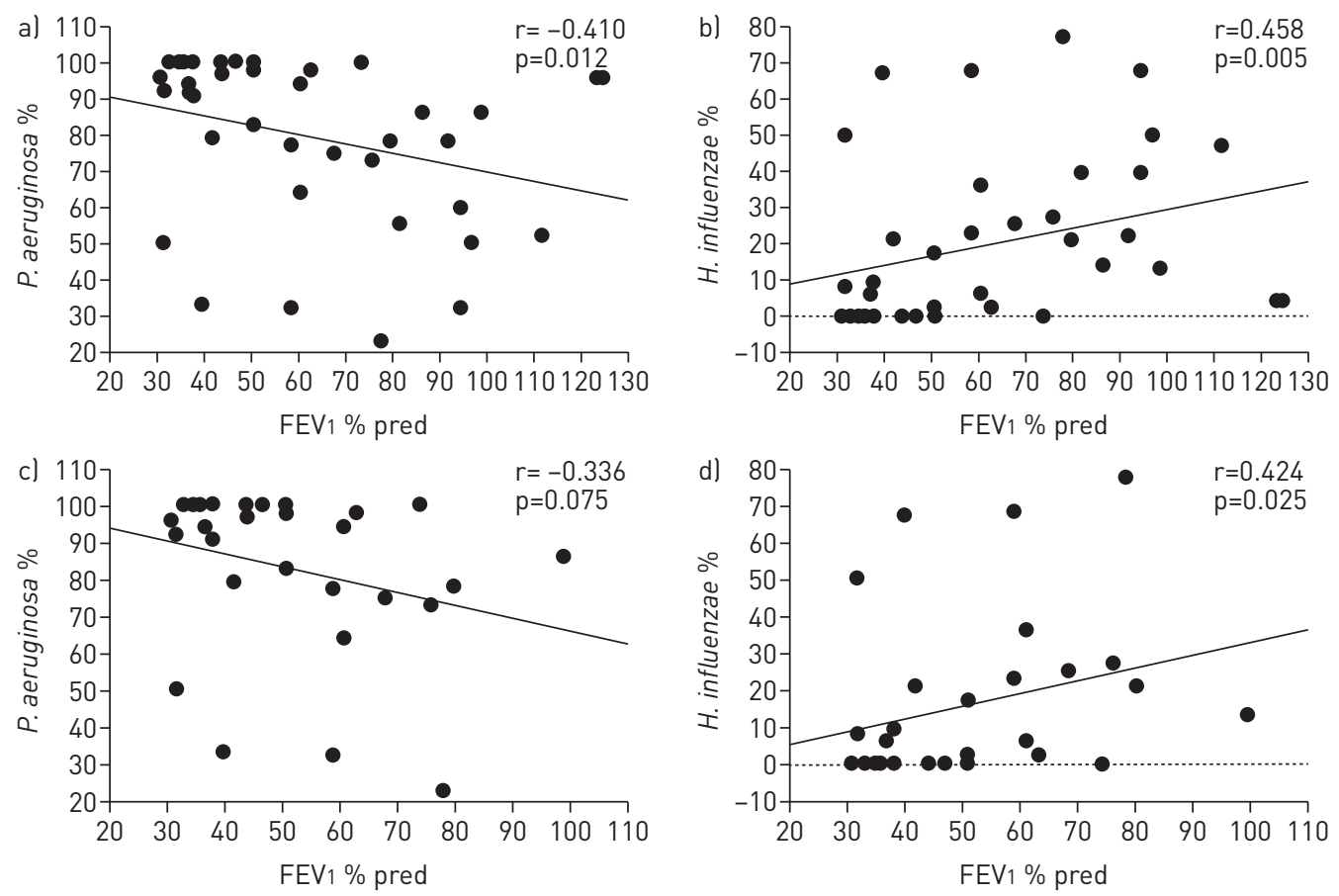

FIGURE 3 Regression analysis performed in $a, b)$ all smokers and $c$, d) patients with chronic obstructive pulmonary disease (COPD) alone showing correlations between forced expiratory volume in $1 \mathrm{~s}$ (FEV1) \% pred lung functional values and percentage of $a, c)$ Pseudomonas aeruginosa and b, d)Haemophilus influenzae. In the bronchial mucosa increased values of bronchial obstruction were associated with an increased percentage of $P$. aeruginosa in all smokers, and a decreased percentage of $H$. influenzae in all smokers and patients with COPD. Correlation coefficients were calculated using the Spearman rank method.

in the lamina propria was inversely correlated with $\mathrm{FEV}_{1} \%$ pred $(\mathrm{r}=-0.39 ; \mathrm{p}=0.019)$ and positively correlated with the numbers of $\mathrm{CD}^{+}$cells $(\mathrm{r}=0.538 ; \mathrm{p}=0.044)$.

Interestingly, in all smokers, the bronchial load of $P$. aeruginosa was inversely correlated with FEV $1 \%$ pred $(\mathrm{r}=-0.41 ; \mathrm{p}=0.012)$ (figure 3 ), whereas the reverse effect was seen with the bronchial load of $H$. influenzae, which was positively correlated with $\mathrm{FEV}_{1} \%$ pred $(\mathrm{r}=0.458 ; \mathrm{p}=0.005)$ (figure 3$)$. This association was maintained in the COPD patient group when studied separately $(r=0.424 ; \mathrm{p}=0.025)$.

No other statistically significant correlations were found between clinical parameters, expression of bacterial receptors, number of inflammatory cells and bacterial load.

\section{Discussion}

We have shown here that TLR4 and NOD1 protein expression is enhanced in the bronchial mucosa of patients with severe/very severe COPD compared with control subjects. In addition, the bronchial epithelial expression of TLR4 correlates positively with the numbers of $\mathrm{CD} 4^{+}$and $\mathrm{CD} 8^{+}$cells in the bronchial mucosa and with the degree of airflow obstruction. NOD1 expression also correlated with $\mathrm{CD} 8^{+}$cell numbers. The degree of airflow obstruction was positively correlated with an increased load of $P$. aeruginosa and a decreased load of $H$. influenzae in the bronchial biopsies in all smokers and in patients with stable COPD.

A previous study found no significant differences in TLR4 expression in the bronchial mucosa of mild/ moderate stable COPD patients compared with control subjects, while the percentage of $\mathrm{CD}^{+}$cells co-expressing TLR4 was increased [18]. The difference between the results reported here could be due to the low number of COPD $(n=8)$ and control subjects $(n=5)$ studied [18], and also due to the different severity of the COPD patients. In all smokers and patients with COPD, we found a significant positive correlation between TLR4 epithelial expression and numbers of $\mathrm{CD}^{+}$and $\mathrm{CD}^{+}$cells in the lamina propria, showing an association between bronchial inflammation and upregulation of TLR4 in stable COPD. Furthermore, in agreement with our present data, increased TLR4 expression was reported by Western blotting in GOLD stage IV COPD patients compared with control nonsmokers [19]. In contrast, LEE et al. [20] reported decreased TLR4 levels associated with increased bronchial obstruction and increased emphysema score on lung lysates of smokers, confirming the need for further investigations to correctly position our present data. Here, we showed that $\mathrm{CD} 8^{+}, \mathrm{CD} 8^{+}$and $\mathrm{CD} 31^{+}$cells mainly 


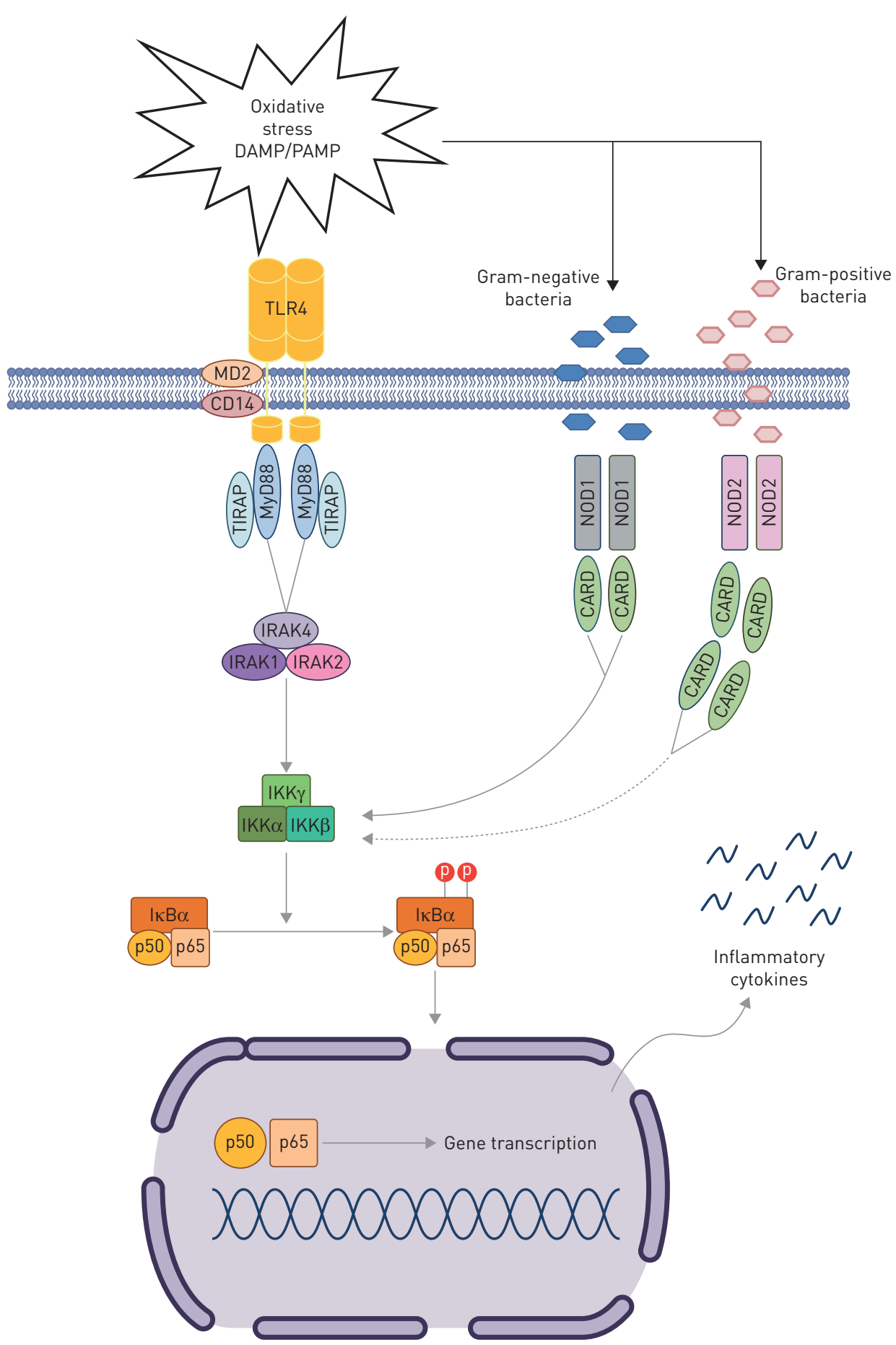

FIGURE 4 Toll-like receptor 4 (TLR4) and nucleotide-binding oligomerisation domain 1 (NOD1) signalling in chronic obstructive pulmonary disease (COPD). In the presence of concomitant oxidative stress stimuli, pathogen-associated molecular patterns (PAMPs) from microorganisms and endogenous molecules termed danger-associated molecular patterns (DAMPs) stimulate TLR4, leading to the recruitment of the TLR signalling adaptor myeloid differentiation primary response protein 88 (MyD88) and the adapter molecule Toll-interleukin-1 receptor domain-containing adaptor protein (TIRAP). The MyD88-dependent pathway recruits the interleukin-1 receptor-associated kinase (IRAK) family of proteins that leads to $\mathrm{I} B \mathrm{~B}$ phosphorylation, resulting in the activation and nuclear translocation of NF- $\mathrm{KB}$ (p50/p65) which can be responsible for the overexpression of numerous inflammatory genes. TLR4, MyD88, TIRAP and p65 (NF- $\mathrm{kB}$ ) result in increased COPD patients. Bacterial peptidoglycan-derived peptides $\gamma$-D-glutamyl-meso-diaminopimelic acid and muramyl dipeptide are recognised by the NOD cytosolic receptors NOD1 and NOD2. Through caspase recruitment domain (CARD)-CARD interactions, NOD1 and NOD2 may stimulate the downstream I $\mathrm{kB}$ kinase (IKK) complex

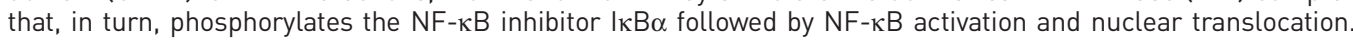
Gram-negative bacteria preferentially activate NOD1, which was found upregulated in our present study in COPD patients. 
contributed to the upregulation of TLR4 and NOD1 in bronchial biopsies of COPD patients. In agreement, using flow cytometric analysis, $\mathrm{CD}^{+}$cells co-expressing TLR4 were also increased in the peripheral lung tissue of COPD patients compared with control smokers [21].

TLR4 recognises LPS, the major surface component of Gram-negative bacteria [5]. Lipid A is the proinflammatory component of LPS and TLR4 is required for the recognition of lipid A of P. aeruginosa [22], suggesting that its overexpression in the bronchial epithelium of severe/very severe stable COPD patients may be important for sensing and responding to persistent colonisation of the lower airways of these patients [23]. Interestingly, in vitro, TLR4 activates NF- $\kappa \mathrm{B}$, and propagates and maintains oxidative/ nitrosative cellular stress, which are both involved in the pathogenesis of stable COPD $[1,24]$.

Oxidative stress is more pronounced in advanced COPD [1], and in vitro both tobacco smoking exposure [18] and oxidative stress [25] may upregulate TLR4 expression. In our in vitro experiments, using human bronchial epithelial cells (16HBE) treated with $\mathrm{H}_{2} \mathrm{O}_{2}$, we showed that oxidative stress induced TLR4 mRNA. Recent evidence in smoking mice [26]. Furthermore, ozone- indicates that cigarette smoke significantly enhanced tlr4 mRNA expression after 4 and 12 weeks $(1.77$ - and 1.53-fold, respectively)enhanced tlr4 mRNA in the lungs of mice after 6 weeks of exposure is completely ablated by treatment with $\mathrm{N}$-acetylcysteine (I.M. Adcock, unpublished data). The data, taken together, indicate that increased oxidative stress could be capable of upregulating TLR4 also in the bronchi of stable COPD patients, although specific studies in humans need to be performed to confirm this hypothesis.

We also demonstrated increased expression of NOD1 in the bronchial epithelium and lamina propria of stable COPD patients compared with control subjects, suggesting an involvement of this cytosolic protein in the recognition process of bacterial cell wall components in the bronchial mucosa of patients with stable COPD [27]. In vitro human bronchial epithelial cells challenged with $M$. catarrhalis show an increased CXCL8 expression that is blocked by NOD1 inhibitors [28]. In addition, in vitro NOD1 agonists activate $\mathrm{NF}-\kappa \mathrm{B}$ in human endothelial cells [29], supporting the role of NOD1 in sustaining bronchial inflammation.

The increased expression of MyD88 in the bronchial epithelium of patients with severe/very severe stable COPD compared with control smokers with normal lung function, without significant differences in CD14 expression, suggests the involvement of a MyD88-dependent downstream signalling pathway in the immunopathology of the bronchial mucosa of stable COPD patients. This is in keeping with our data showing increased expression of TIRAP in the bronchial epithelium of our severe/very severe COPD patients, an index of MyD88-dependent pathway activation (figures 1 and 4) [15].

The decreased $H$. influenzae load observed in the bronchial mucosa of our patients with severe/very severe stable COPD compared with mild/moderate COPD and control smokers with normal lung function is in keeping with previous studies showing a fundamental role of TLR4 activation in the clearance of this bacteria from the mouse lung $[30,31]$. This is also in agreement with previous studies showing that $H$. influenzae is virtually absent in severe/very severe COPD lung tissues and increased in milder forms of COPD [32]. The absence of $H$. influenzae may also provide a niche for colonisation by other pathogenic bacteria such as new strains of $P$. aeruginosa $[32,33]$.

Our data on the bronchial bacterial load are discordant with a previous study performed in lung parenchymal tissues. This showed no significant differences in total bacterial load between advanced stable COPD and control subjects [34], and may reflect the different lower airway compartment examined. Previous studies have clearly demonstrated a progressive decrease of the total bacterial load from the upper to lower airways and lung parenchyma $[32,33,35]$, and this makes it more difficult to identify significant differences between patients with stable COPD of different severities and control subjects in the presence of very low levels of total bacterial load. This difference may also influence the related immune host response developing in the bronchi and lung tissue (different compartments) of COPD patients when compared with control subjects. These considerations are also reinforced by the data of CABRERA-RUBIO et al. [36] showing that in patients with stable COPD the microbiota composition obtained by the analysis of bronchial biopsies and bronchoalveolar lavage better represents the lower airway bacterial composition compared with the analysis of sputum and bronchial aspirate samples [36].

Neither P. aeruginosa nor $H$. influenzae, expressed as absolute number or as percentage, were correlated with inflammatory cells $\left(\mathrm{CD}^{+}, \mathrm{CD}^{+} 8^{+}\right.$neutrophils) or bacterial-related molecules (TLR4, NOD1) mainly expressed in the bronchial biopsies. This finding suggests that in stable disease the microbiota may not be directly related to the classical COPD inflammatory response developing in the bronchial mucosa. This seems to be in contrast to the situation during COPD exacerbations where a concomitant increase of bronchial inflammation [37], microbiota load [38] and TLR4 expression [39] has been observed. However, a comprehensive study of pathogen-related bacteria and related inflammatory response in bronchial biopsies of exacerbated COPD patients is lacking. Furthermore, changes in microbial composition in the 
lung and gut have been linked to organ-related alterations of the immune responses. However, no studies have investigated changes in the gut microbiota of patients with COPD of increasing severity [40].

It is interesting to note that certain single nucleotide polymorphisms of the NOD2 gene were associated with more severe disease in Japanese COPD patients [41] and this area deserves more research in the future. Furthermore, in our current study, both IRAK4 and phospho-IRAK1, which favour NF- $\mathrm{BB}$ nuclear activation [11], were overexpressed in the bronchial epithelium and lamina propria of all subjects studied. This indicates that the bronchial mucosa is activated in COPD (figures 1 and 4). A more expansive study using next-generation sequencing may determine the precise differences in inflammation and immunity in these patients.

As a limitation of this study, and in agreement with other authors [33], we cannot exclude a bias in the quantification of the bacterial load due to repeated antibiotic treatments, particularly in severe/very severe COPD patients, even though a 1-month washout period from antibiotic treatments was applied in our protocol study. In addition, the study was not powered to detect the effect of smoking cessation on these parameters and further larger studies are required to confirm these data as well as the subgroup analysis performed here.

In conclusion, the overexpression of TLR4 and NOD1 in the bronchial epithelium of patients with severe/ very severe stable COPD, associated with increased bronchial inflammation and $P$. aeruginosa bacterial load, may play a role in the pathogenesis of the disease.

\section{Acknowledgements}

Author contributions: A. Di Stefano, F.L.M. Ricciardolo, G. Caramori and I.M. Adcock contributed to the study design, interpretation of the data and writing the manuscript; P.J. Barnes, K.F. Chung, F. Andò, P. Brun, A. Leonardi, L. Righi, D. Vallese, F. Cappello and B. Balbi contributed to a critical revision of the manuscript; I. Gnemmi, D. Vallese and A. Di Stefano contributed to the production of the data and accuracy of the data analysis.

\section{References}

1 Barnes PJ. Cellular and molecular mechanisms of chronic obstructive pulmonary disease. Clin Chest Med 2014; 35: 71-86.

2 Belkaid Y, Hand TW. Role of the microbiota in immunity and inflammation. Cell 2014; 157: 121-141.

3 Iwasaki A, Medzhitov R. Control of adaptive immunity by the innate immune system. Nat Immunol 2015; 16: 343-353.

4 Fukata M, Vamadevan AS, Abreu MT. Toll-like receptors (TLRs) and Nod-like receptors (NLRs) in inflammatory disorders. Semin Immunol 2009; 21: 242-253.

5 Takeda K, Akira S. Toll-like receptors in innate immunity. Int Immunol 2005; 17: 1-14.

6 Lund J, Sato A, Akira S, et al. Toll-like receptor 9-mediated recognition of Herpes simplex virus-2 by plasmacytoid dendritic cells. J Exp Med 2003; 198: 513-520.

7 Ranoa DR, Kelley SL, Tapping RI. Human lipopolysaccharide-binding protein (LBP) and CD14 independently deliver triacylated lipoproteins to Toll-like receptor 1 (TLR1) and TLR2 and enhance formation of the ternary signaling complex. J Biol Chem 2013; 288: 9729-9741.

8 Girardin SE, Boneca IG, Viala J, et al. Nod2 is a general sensor of peptidoglycan through muramyl dipeptide (MDP) detection. J Biol Chem 2003; 278: 8869-8872.

9 Hemmi H, Kaisho T, Takeda K, et al. The roles of Toll-like receptor 9, MyD88, and DNA-dependent protein kinase catalytic subunit in the effects of two distinct CpG DNAs on dendritic cell subsets. J Immunol 2003; 170: 3059-3064.

10 Ito T, Amakawa R, Kaisho T, et al. Interferon-alpha and interleukin-12 are induced differentially by Toll-like receptor 7 ligands in human blood dendritic cell subsets. J Exp Med 2002; 195: 1507-1512.

11 Takeuchi O, Takeda K, Hoshino K, et al. Cellular responses to bacterial cell wall components are mediated through MyD88-dependent signaling cascades. Int Immunol 2000; 12: 113-117.

12 Kawai T, Adachi O, Ogawa T, et al. Unresponsiveness of MyD88-deficient mice to endotoxin. Immunity 1999; 11: $115-122$.

13 Schnare M, Holt AC, Takeda K, et al. Recognition of CpG DNA is mediated by signaling pathways dependent on the adaptor protein MyD88. Curr Biol 2000; 10: 1139-1142.

14 Häcker H, Vabulas RM, Takeuchi $\mathrm{O}$, et al. Immune cell activation by bacterial CpG-DNA through myeloid differentiation marker 88 and tumor necrosis factor receptor-associated factor (TRAF)6. J Exp Med 2000; 192: 595-600.

15 Yamamoto M, Sato S, Hemmi H, et al. Essential role for TIRAP in activation of the signalling cascade shared by TLR2 and TLR4. Nature 2002; 420: 324-329.

16 Di Stefano A, Caramori G, Barczyk A, et al. Innate immunity but not NLRP3 inflammasome activation correlates with severity of stable COPD. Thorax 2014; 69: 516-524.

17 Vallese D, Ricciardolo FL, Gnemmi I, et al. Phospho-p38 MAPK expression in COPD patients and asthmatics and in challenged bronchial epithelium. Respiration 2015; 89: 329-342.

18 Nadigel J, Préfontaine D, Baglole CJ, et al. Cigarette smoke increases TLR4 and TLR9 expression and induces cytokine production from $\mathrm{CD}^{+} \mathrm{T}$ cells in chronic obstructive pulmonary disease. Respir Res 2011; 12: 149.

19 An $\mathrm{CH}$, Wang XM, Lam HC, et al. TLR4 deficiency promotes autophagy during cigarette smoke-induced pulmonary emphysema. Am J Physiol Lung Cell Mol Physiol 2012; 303: L748-L757.

20 Lee SW, Kim DR, Kim TJ, et al. The association of down-regulated toll-like receptor 4 expression with airflow limitation and emphysema in smokers. Respir Res 2012; 13: 106.

21 Freeman CM, Martinez FJ, Han MK, et al. Lung $\mathrm{CD}^{+} \mathrm{T}$ cells in COPD have increased expression of bacterial TLRs. Respir Res 2013; 14: 13. 
22 Ernst RK, Hajjar AM, Tsai JH, et al. Pseudomonas aeruginosa lipid A diversity and its recognition by Toll-like receptor 4. J Endotoxin Res 2003; 9: 395-400.

23 Gallego M, Pomares X, Espasa M, et al. Pseudomonas aeruginosa isolates in severe chronic obstructive pulmonary disease: characterization and risk factors. BMC Pulm Med 2014; 14: 103.

24 Karki R, Igwe OJ. Toll-like receptor 4-mediated nuclear factor kappa B activation is essential for sensing exogenous oxidants to propagate and maintain oxidative/nitrosative cellular stress. PLoS One 2013; 8: e73840.

25 Lucas K, Maes M. Role of the Toll Like receptor (TLR) radical cycle in chronic inflammation: possible treatments targeting the TLR4 pathway. Mol Neurobiol 2013; 48: 190-204.

26 Haw TJ, Starkey MR, Nair PM, et al. A pathogenic role for tumor necrosis factor-related apoptosis-inducing ligand in chronic obstructive pulmonary disease. Mucosal Immunol 2016; 9: 859-872.

27 Leissinger M, Kulkarni R, Zemans RL, et al. Investigating the role of nucleotide-binding oligomerization domain-like receptors in bacterial lung infection. Am J Respir Crit Care Med 2014; 189: 1461-1468.

28 Slevogt H, Seybold J, Tiwari KN, et al. Moraxella catarrhalis is internalized in respiratory epithelial cells by a trigger-like mechanism and initiates a TLR2- and partly NOD1-dependent inflammatory immune response. Cell Microbiol 2007; 9: 694-707.

29 Gatheral T, Reed DM, Moreno L, et al. A key role for the endothelium in NOD1 mediated vascular inflammation: comparison to TLR4 responses. PLoS One 2012; 7: e42386.

30 Wang X, Moser C, Louboutin JP, et al. Toll-like receptor 4 mediates innate immune responses to Haemophilus influenzae infection in mouse lung. J Immunol 2002; 168: 810-815.

31 Wieland CW, Florquin S, Maris NA, et al. The MyD88-dependent, but not the MyD88-independent, pathway of TLR4 signaling is important in clearing nontypeable Haemophilus influenzae from the mouse lung. J Immunol 2005; 175: 6042-6049.

32 Sze MA, Dimitriu PA, Suzuki M, et al. Host response to the lung microbiome in chronic obstructive pulmonary disease. Am J Respir Crit Care Med 2015; 192: 438-445.

33 Dickson RP, Erb-Downward JR, Huffnagle GB. Homeostasis and its disruption in the lung microbiome. Am J Physiol Lung Cell Mol Physiol 2015; 309: L1047-L1055.

34 Sze MA, Dimitriu PA, Hayashi S, et al. The lung tissue microbiome in chronic obstructive pulmonary disease. Am J Respir Crit Care Med 2012; 185: 1073-1080.

35 Charlson ES, Bittinger K, Haas AR, et al. Topographical continuity of bacterial populations in the healthy human respiratory tract. Am J Respir Crit Care Med 2011; 184: 957-963.

36 Cabrera-Rubio R, Garcia-Núñez M, Setó L, et al. Microbiome diversity in the bronchial tracts of patients with chronic obstructive pulmonary disease. J Clin Microbiol 2012; 50: 3562-3568.

37 Saetta M, Di Stefano A, Maestrelli P, et al. Airway eosinophilia in chronic bronchitis during exacerbations. Am J Respir Crit Care Med 1994; 150: 1646-1652.

38 D'Anna SE, Balbi B, Cappello F, et al. Bacterial-viral load and the immune response in stable and exacerbated COPD: significance and therapeutic prospects. Int J Chron Obstruct Pulmon Dis 2016; 11: 445-453.

39 Pace E, Ferraro M, Giarratano A, et al. TLR4 up-regulation and reduced Foxp3 expression in mechanically ventilated smokers with obstructive chronic bronchitis. COPD 2013; 10: 147-155.

40 Budden KF, Gellatly SL, Wood DL, et al. Emerging pathogenic links between microbiota and the gut-lung axis. Nat Rev Microbiol 2017; 15: 55-63.

41 Kinose D, Ogawa E, Hirota T, et al. A NOD2 gene polymorphism is associated with the prevalence and severity of chronic obstructive pulmonary disease in a Japanese population. Respirology 2012; 17: 164-171. 